\title{
Factors affecting adherence of end-stage renal disease patients to an exercise programme
}

\author{
A. Williams ${ }^{1}$, R. Stephens ${ }^{1}$, T. McKnight ${ }^{2}$ MD and S. Dodd ${ }^{1}$ PhD \\ 1 Department of Kinesiology, Louisiana State University, Baton Rouge, Louisiana, USA \\ 2 E. K. Long Hospital, Baton Rouge, Louisiana, USA
}

\begin{abstract}
Recently it has been shown that regular exercise is both physiologically and psychologically beneficial to patients with end-stage renal disease (ESRD). However, ESRD patients traditionally have a high non-adherence level to their self-care and medical regimens. To date, their adherence to exercise programmes has not been studied. Background information about employment, medical history, previous exercise habits and locus of control was obtained from 40 volunteer ESRD patients who started exercise at home. Twenty-eight participants maintained the exercise programme, consisting of aerobic activity lasting an average of $\mathbf{2 5}$ min, four times per week, for 12 weeks. The adherent patients were found to have encouraging support groups (75 versus 25\%), to be between 41 and 60 years of age (64 versus 33\%), to have been on dialysis for between 2 and 5 years, and to have loci of control (feeling of control over life events) classed as 'internal' (68 versus 25\%). Factors such as sex, race, employment status and depression were found to have little influence on adherence. The major finding of this study was that patients adherent to exercise could be distinguished by unique psychological and psychosocial factors, and that adherence in this population was higher (70 compared with 50\%) than some estimates for the general population.
\end{abstract}

Keywords: Renal disease, haemodialysis, adherence, exercise

Chronic renal failure results from structural renal damage which leaves the body unable to excrete metabolites, resulting in the uraemic syndrome. These end-stage renal disease (ESRD) patients suffer from psychological, physiological and psychosocial disorders that have a direct relationship with the lifestyle changes brought about by dialysis treatment $^{1}$.

ESRD patients constitue a medical population that is extremely non-adherent in following self-care and medical regimens. The costs of this non-adherence are extensive, ranging from compensation costs to lost productivity and the perpetuation of disease ${ }^{2}$. The data show that, on average, $50 \%$ of patients on dialysis either do not take their medications or take

Address for correspondence: Dr Stephen Dodd, Department of Kinesiology, Louisiana State University, Baton Rouge, Louisiana, USA

(C) 1991 Butterworth-Heinemann Ltd.

0306-3674/91/020090-04 them incorrectly ${ }^{3}$. Medical appointments are missed $20-50 \%$ of the time and patients show a great reluctance to change bad habits, like smoking or drinking alcohol ${ }^{3}$. There is also a high incidence of those who continue to eat and drink as they did before onset of disease, placing themselves at great risk and increasing their physical discomfort. ESRD patients are also poor attenders at the dialysis treatment clinic.

Over the past several years it has been demonstrated that exercise is beneficial for ESRD patients ${ }^{1,4}$. The exercises have been supervised in groups where frequency, intensity and duration of exercise are specified. Most of these studies agree that exercise training with ESRD patients brings about an improved exercise capacity ${ }^{5-7}$. Hypertension, a prevalent condition in ESRD, has consistently been shown to decrease with exercise, with some patients decreasing their hypertensive medication and others being taken off entirely ${ }^{5,7}$. As a result of some exercise programmes, it has been shown that very low density lipoprotein levels decrease and high density lipoprotein levels increase ${ }^{5-8}$. Haematocrit and red blood cell count have been shown, in some cases, to be elevated as a result of a progressive endurance training in this population ${ }^{5,6,8}$.

However, it is difficult to get haemodialysis patients to start an exercise programme for several reasons. First, few patients feel well enough to exercise and do not understand that exercise can help alleviate many of their symptoms. Patients must want to begin exercises and believe that they are capable of doing them. If they do not believe this, they will not be able to maintain a programme even if they have a strong desire to do so 9,10 . Second, this population is extremely susceptible to colds, viral infections and influenza; many must have frequent blood transfusions or be hospitalized due to complications with the shunt site or side-effects of dialysis. This makes it extremely difficult for them to maintain their exercises and they may lose incentive and motivation when they are forced to restart an exercise programme after an illness or surgery. Third, in the ESRD population, it is difficult to conduct organized exercise classes or sessions. Many ESRD patients are not willing to spend this additional time on exercises when they already spend a great amount of time on dialysis. Others cannot drive and find an exercise programme inaccessible. 
Thus, while ESRD patients traditionally have a high non-adherence level with regard to their medical regimens, to date their adherence to exercise programmes has not been studied. Therefore, the purpose of this study was to determine the adherence rate to exercise in ESRD patients.

\section{Methods}

A voluntary 12-week exercise programme was begun for interested patients at a haemodialysis clinic. Of 120 patients attending the clinic, 55 expressed interest in beginning an exercise programme at home or while on dialysis, 50 of whom were given approval by the staff physician. Ten withdrew after medical clearance, but before the programme began, leaving $\mathbf{4 0}$ patients to begin the exercises.

The patients all visited the dialysis centre three times a week for 3-4h of chemical haemodialysis. Initially, each patient was interviewed and encouraged to participate in the exercise programme. Participants chose the type of aerobic exercise that they most enjoyed and started at a frequency, intensity and duration which they felt they could easily maintain (Table 1): the most frequently chosen exercises were walking, cycling or aerobics.

Each patient was interviewed weekly and advised on how to increase gradually the intensity, frequency and duration of their chosen exercise. As heart rate is not a good index of exercise intensity in this population because of the neuropathy associated with ESRD ${ }^{11}$, Borg's rating of perceived exertion (RPE) scale was used to estimate exercise intensity ${ }^{12}$. This subjective scale has been used as a valid indicator of exercise intensity in instances where heart rate is not obtainable (e.g. pharmacological intervention). Twenty-eight patients were classified as adherent, as they exercised at least 2 days a week for at least $15 \mathrm{~min}$ during the 12-week study. As this patient population is primarily sedentary, it was felt that this represented a true effort on the participant's part to adhere to an exercise programme. The other 12 patients were classed as non-adherent.

Specific background information was collected on all 40 participants regarding employment status, support group involvement, medical history and previous exercise habits ${ }^{13,14}$. Each individual's locus of control was also evaluated ${ }^{10}$. This is the extent to

Table 1. Distribution of activities selected by haemodialysis patients

\begin{tabular}{lc}
\hline Activity & Percentage \\
\hline Walking & 59 \\
Swimming & 4 \\
Aerobics & 6 \\
Cycling & 4 \\
Cycling on dialysis & 4 \\
Walking and cycling & 9 \\
Walking and aerobics & 10 \\
Varied* & 4 \\
\hline
\end{tabular}

* Defined as jogging, walking, swimming, cycling, sporting games and other activities which the person expects that he or she can control life's events (internal locus of control) as opposed to the expectancy that life's events are the result of external factors such as chance, luck or fate (external locus of control). The background information was examined to determine if these factors had any effect on a participant's adherence levels. Initially, individuals were also asked to complete a Beck depression inventory to determine if depression had any effect on adherence.

Statistical analysis consisted of unpaired Student $t$ tests to test for significant differences between groups for each of the variables. Significance was set at $P<0.05$.

\section{Results}

Participants' adherence levels were examined in conjunction with their background information to determine whether certain factors influenced patient adherence more than others. There was no significant difference in age between groups: mean (s.e.m.) $=48.23(2.2)$ years for the adherent group and 56.10 (3.7) years for the non-adherent group. The mean time spent per exercise session was $25(2.0) \mathrm{min}$, a mean of $3.6(0.46)$ days per week.

Table 2 summarizes selected characteristics of both the adherent and non-adherent groups. As shown, there was no significant difference in sex, race or employment status between the adherent and nonadherent groups. The adherent group was statistically more likely $(P<0.05)$ to have a support group. The breakdown of body-weight indicated no significant difference between groups for the over- and under-weight. When ages were categorized, the adherent group had a significantly greater percentage $(P<0.05)$ of subjects in the $21-40$ age group. A significantly greater percentage $(P<0.05)$ of patients in the adherent group had been on dialysis for 2-5 years. However, there were no patients in the non-adherent group who had been on dialysis for more than 5 years, so no comparison was possible for that category. The adherent group reported significantly an internal locus of control $(P<0.05)$. Finally, the Beck inventory revealed no difference between groups in level of depression when broken down into normal, mild, and severe categories.

The data in Table 3 shows the reasons given by both the patients which were cleared for participation but never started $(n=10)$, and those who were classed as non-adherent $(n=12)$, for not participating. These reasons correspond to those given by dialysis patients for being non-adherent to most of their life regimens.

\section{Discussion}

The fact that there was no significant difference in sex, race and weight between the two groups was not surprising. This is in agreement with the data of Blumenthal et al. ${ }^{13}$, who demonstrated that most external characteristics such as these have little relevance in adherence. 
Although the employed and unemployed groups had equal percentages in adherent and non-adherent groups, it is interesting to note that all of the employed, adherent participants had support groups, internal locus of control and scored in the normal range on the Beck depression inventory. This was not true of the employed, non-adherent group.

Table 2. Comparison of characteristics in the adherent and non-adherent groups

\begin{tabular}{|c|c|c|c|c|}
\hline \multirow[t]{2}{*}{ Characteristic } & \multicolumn{2}{|c|}{$\begin{array}{l}\text { Adherent } \\
(\mathrm{n}=28)\end{array}$} & \multicolumn{2}{|c|}{$\begin{array}{l}\text { Non-adherent } \\
\quad(\mathrm{n}=12)\end{array}$} \\
\hline & $\%$ & No. & $\%$ & No. \\
\hline \multicolumn{5}{|l|}{$\overline{\text { Sex }}$} \\
\hline Male & 61 & (17) & 42 & (5) \\
\hline Female & 39 & (11) & 58 & (7) \\
\hline \multicolumn{5}{|l|}{ Race } \\
\hline Black & 75 & (21) & 50 & (6) \\
\hline Caucasian & 25 & (7) & 50 & (6) \\
\hline \multicolumn{5}{|l|}{ Employment status } \\
\hline Retired & 11 & (3) & 8 & (1) \\
\hline Employed & 25 & (7) & 25 & (3) \\
\hline Unemployed & 61 & (17) & 67 & (8) \\
\hline Student & 41 & (1) & 0 & (0) \\
\hline \multicolumn{5}{|c|}{ Support group status* } \\
\hline Support group & 75 & (21) & $25+$ & (3) \\
\hline No support group & 25 & (7) & $75+$ & (9) \\
\hline \multicolumn{5}{|l|}{ Weight $¥$} \\
\hline Over & 21 & (6) & 8 & (1) \\
\hline Under & 7 & (2) & 33 & (4) \\
\hline Normal & 71 & (20) & 58 & (7) \\
\hline \multicolumn{5}{|l|}{ Age (years) } \\
\hline $21-40$ & 21 & (6) & $8+$ & (1) \\
\hline $41-60$ & 64 & (18) & $33+$ & (4) \\
\hline 61 over & 14 & (4) & $58+$ & (7) \\
\hline \multicolumn{5}{|l|}{ Years on dialysis } \\
\hline$<2$ & 25 & (7) & $67 t$ & (8) \\
\hline $2-5$ & 68 & (19) & $42+$ & (5) \\
\hline $6-15$ & 7 & (2) & 0 & (0) \\
\hline \multicolumn{5}{|l|}{ Locus of control ${ }^{\S}$} \\
\hline Internal & 68 & (19) & $25+$ & (3) \\
\hline External & 21 & (6) & $58+$ & (7) \\
\hline Borderline & 11 & (3) & 17 & (2) \\
\hline \multicolumn{5}{|c|}{ Beck inventory $(n=20)$} \\
\hline Normal & 70 & (7) & 30 & (3) \\
\hline Mild/moderate & 30 & (3) & 60 & (6) \\
\hline Severe & 0 & (0) & 10 & (1) \\
\hline
\end{tabular}

* Support group is defined as one of more individuals providing positive reinforcement and encouragement

+ Significantly different from the adherent group at $P<0.005$ ¥ Classified by $10 \%$ above or below mean weight for height $\S$ Locus of control as determined by personal interview

Table 3. Reasons given by dialysis patients for not participating inthe exercise programme

\begin{tabular}{lc}
\hline Reason & $\begin{array}{c}\text { Percentage } \\
(\mathrm{n}=22)\end{array}$ \\
\hline Lack of time & 33 \\
Lack of energy & 25 \\
Too much trouble & 17 \\
Depression & 17 \\
Death & 8 \\
\hline
\end{tabular}

The principal finding of the present investigation was that the majority of the participants who developed and maintained exercise programmes (70\%) were distinguished from the non-adherent participants by a set of physiological, psychosocial and psychological characteristics. Thus, $75 \%$ of the adherent participants were found to have a support group encouraging their exercise progress, while only $25 \%$ of the non-adherent patients had support group encouragement. This finding is consistent with previous investigations which also found that behaviour adherence/compliance increased when support groups became actively involved ${ }^{15-17}$.

Age was found to be a significant indicator of exercise adherence. Patients in the age range 41-60 years had the highest adherence rate, while those in the 61-85 years group had the lowest. A plausible explanation for this finding is that the majority of patients aged 61-85 years were debilitated and most forms of exercise were very difficult. Many had been inactive for a long time and could not be convinced of the efficacy of exercises.

The length of time patients had been on dialysis was found to be indicative of exercise adherence. This is similar to the results of previous general compliance studies $14,18,19$, where it has been found that the patients who had been on haemodialysis between 2 and 5 years had a higher rate of adherence to self-care and medical regimens than those who had been on the treatment less than 2 years or more than 5 years. Maher ${ }^{19}$ and Cassileth ${ }^{14}$ found that patients who had greater depression and loss of control were those patients who had been on dialysis less than 2 years. In our investigation, similar characteristics were found to exist in those patients with a poor level of exercise adherence.

An explanation for this relationship may be that as time passes, many patients slowly regain their feelings of self-control (i.e. as demonstrated in the patients who had been on the treatment for more than 2 years). It is probable that those who had been on dialysis longer had more time to gain support from friends and family members than those at the beginning of the treatment who may have been unsure of the limitations and restrictions that dialysis might impose. These patients also had more time to become accustomed to the constant medical procedures. They had a longer period of time over which they could define their centre of control as within themselves rather than with someone or something else.

A significant number (68\%) of the adherent patients were found to have an internal locus of control. At interview, they expressed that they were in control of their own lives. By contrast, $58 \%$ of the non-adherents had an external locus of control, many feeling that misfortune, bad luck or even the disease itself controlled the outcome of their lives. Agashua et al. ${ }^{18}$ suggests that a patient's attitude, beliefs and orientation make the difference between invalidism and rehabilitation.

The Beck depression inventory is clinically derived and designed to measure both the attitudes and symptoms which appear to be specific for depression and those which were consistent with descriptions in 
the psychiatric literature while not reflecting any theory for the cause of the depression. Of the 40 participants, 22 agreed to complete a Beck depression inventory. Two questionnaires were invalid and unable to be scored. Nine participants $(45 \%)$ scored in the mild to moderately depressed range $(P>0.05)$ and one scored in the severe range; the remaining ten were all normal. This trend is similar to the findings of Kutner et al. ${ }^{20}$. In their assessment of dialysis patients, $47.7 \%$ scored in the normal range while the remainder scored as either symptomatic or clinically depressed. Our study demonstrated that the more adherent patients were the ones $(70 \%)$ that scored in the normal range. In 1986, Carney et al. ${ }^{21}$ had similar results in which the more physically active, comparable to our adherent group, scored in the normal range on the Minnesota multiphasic personality inventory, while inactive, sedentary patients scored in the depressed range.

All the 28 adherent patients were frequently affected during the 3-month exercise period by colds, influenza, viral infections and minor surgery. This population is extremely susceptible to such afflictions and their recovery rate is $2-3$ times longer than that of a normal individual. Ten of the 40 participants were hospitalized during the 12-week period (5 adherents and 5 non-adherents). The adherent patients began or continued to exercise after returning from hospital. This may have been due to support group encouragement and the individual's loci of control, for all who returned to exercise had an internal loci of control, feeling that they were in control of their own lives.

In summary, this study supports other research studies on adherence levels of haemodialysis patients and other exercise studies ${ }^{13,18,22}$. In fact, the adherence level of these patients is higher (70 versus $50 \%)$ than some reports of adherence for the normal population. It confirms that support groups and personal ego strength are major determinants of haemodialysis patients' adherence to a medical regimen or an exercise programme ${ }^{19,20,23}$. Exercise has been proven to be a beneficial part of many medical regimens. However, our data indicate that prescribing an exercise programme like any other medical regimen, does not insure that it will be followed. Motivation, personal background and ego should be examined to determine the likelihood of adherence. Where adherence seems unlikely, special counseling may be necessary to improve the adherence rate.

\section{Acknowledgement}

The authors would like to express their appreciation to the staff of BMA, Inc., Baton Rouge, LA, for their tremendous help in the completion of this study.

\section{References}

1 Batelle Human Affairs Research Centres. National kidney dialysis and kidney transplantation study: a summary of results. Contemp Dialysis Neph 1985; 6: 41-7.

2 Cummings C, Nehemkis AM. How society contributed to non-compliance. In: Gerber K, Nehemkis A, eds. Compliance: The Dilemma of the Chronically Ill. New York: Springer, 1986, 13-36.

3 Gerber K. Compliance in the chronically ill: an introduction to the problem. In: Gerber K, Nehemkis A, eds. Compliance: The Dilemma of the Chronically Ill. New York: Springer, 1986, 2-12.

4 Nelson-Worrel JN, Hill MM, Thornbery DR, Shelp WR, Harrington AR, Weinstein AB. Effects of exercise training during haemodialysis. Nephron 1986; 43: 87-92.

5 Goldberg AP, Hagberg J, Delmez JA et al. The metabolic and psychological effects of exercise training in hemodialysis patients. Am J Nut 1980; 33: 1620-8.

6 Goldberg AP, Geltham EM, Gavin JR et al.Exercise training reduces coronary risk and effectively rehabilitates hemodialysis patients. Nephron 1986; 42: 311-16.

7 Hagberg JM, Goldberg AP, Ehasani A, Heath GW, Delmez JA, Harter HR. Exercise training improves hypertension in hemodialysis patients. Am J Nephrol 1983; 3: 209-12.

8 Kutner NG, Cardenas DD, Bower JD. Rehabilitation and the Chronic Renal Disease Patient. New York: Medical and Scientific Books, 1988.

9 Dishman RK, Ickes $W$. Self-motivation and adherence to therapeutic exercise. J Behav Med 1981; 4: 421-38.

10 Pervin LA. Personality: Theory and Research. New York: John Wiley \& Sons, 1984.

11 Ketner A, Goldberg AP, Hagberg JM, Delmez JA, Harter HR. Cardiovascular and metabolic responses to submaximal exercise in hemodialysis patients. Kidney Int 1984; 26: 66-71.

12 Borg GAV. Perceived exertion: a note on history and methods. Med Sci Exer 1973; 5: 90-7.

13 Blumenthal JA, Williams RS, Wallace AG, Williams RB, Needles TL. Physiological and psychological variables predict compliance to prescribed therapy in patients recovering from myocardial infarction. Psychosom Med 1982; 144: 519-27.

14 Cassileth BR, Lusk EJ, Strouse TB. Psychological status in chronic illness: a comparative analysis of six diagnostic groups. N Engl J Med 1984; 311: 506-11.

15 Heinzelmann F, Bagley R. Response to physical activity programs and their effects on health behaviours. Public Health Rep 1970; 85: 905-11.

16 Oldridge NB. Compliance and dropout in cardiac exercise rehabilitation. J Card Rehabil 1984; 4: 166-77.

17 Turk DC, Salovey PH. Adherence: a cognitive-behavioural perspective. In: Gerber K, Nehemkis A, eds. Compliance: The Dilemma of the Chronically Ill. New York: 1986, 68-89.

18 Agashua PA, Lyle RC, Livesley PD, Slade PD, Winney RJ, Irwin M. Predicting dietary non-compliance of dialysis patients on intermittent dialysis. I Psychosom Res 1981; 5: 289-301.

19 Mahler BA, Lamping DL, Dickinson CA, Murawski BJ, Olivier DC, Santiago GC. Psychosocial aspects of chronic hemodialysis: the national cooperative study. Kidney Int 1983; 23: $\mathrm{S} 50-7$.

20 Kutner NG, Fair PL, Kutner MH. Assessing depression and anxiety in chronic hemodialysis patients. I Pyschosom Med 1984; 28: 23-9.

21 Carney RM, Wetzel RD, Hagberg J, Goldberg AP. The relationship between depression and aerobic capacity in hemodialysis patients. Psychosom Med 1986; 48: 143-7.

22 Andrew GM, Oldridge NB, Parker JO. Reasons for dropout from exercise programs in post coronary patients. Med Sci Sports Exer 1981; 11: 376-8.

23 Wankel LM. Decision making and social support strategies, for increasing exercise involvement. J Card Rehabil 1984; 4: 124-35. 